\title{
Field-based hearing measurements of two seabird species
}

\author{
T. Aran Mooney ${ }^{1, *}$, Adam Smith ${ }^{1}$, Ole Naesbye Larsen², Kirstin Anderson Hansen ${ }^{2}$, Magnus Wahlberg ${ }^{2}$ \\ and Marianne H. Rasmussen ${ }^{3}$
}

\begin{abstract}
Hearing is a primary sensory modality for birds. For seabirds, auditory data is challenging to obtain and hearing data are limited. Here, we present methods to measure seabird hearing in the field, using two Alcid species: the common murre Uria aalge and the Atlantic puffin Fratercula arctica. Tests were conducted in a portable semi-anechoic crate using physiological auditory evoked potential (AEP) methods. The crate and AEP system were easily transportable to northern Iceland field sites, where wild birds were caught, sedated, studied and released. The resulting data demonstrate the feasibility of a field-based application of an established neurophysiology method, acquiring high quality avian hearing data in a relatively quiet setting. Similar field methods could be applied to other seabirds, and other bird species, resulting in reliable hearing data from a large number of individuals with a modest field effort. The results will provide insights into the sound sensitivity of species facing acoustic habitat degradation.
\end{abstract}

KEY WORDS: Noise, Auditory, Soundscape, Evoked potentials, Masking

\section{INTRODUCTION}

Birds are well known for their acoustic communication and their hearing abilities have been intensively investigated for decades. Historically, most auditory work has focused on songbirds and other model taxa such as the barn owl (Dooling, 1992; Dooling et al., 2000; Kettler et al., 2016; Payne, 1971). There are relatively few auditory studies on prominent non-passerine taxa, such as marine birds, which comprise $\sim 4 \%$ of all avian species. This is perhaps surprising as seabirds are conspicuous top predators that fill important niches and are thought be sentinels of ocean change (Burger and Gochfeld, 2004; Croxall et al., 2012); thus, understanding their sensory ecology is an important part of understanding coastal ocean communities. However, many marine avian species are difficult to access or not easily kept in captivity for psychophysical training. Consequently, field-based hearing studies would facilitate examination of the acoustic sensory systems of additional species and those for which there are conservation or noise-related concerns.

Examining bird hearing is important given the growing realization that anthropogenic noise is encroaching on bird habitats and impacting species in myriad ways. Recent data, primarily on songbirds, has shown noise may have multiple impacts, including reduced species diversity (Proppe et al., 2013;

\footnotetext{
${ }^{1}$ Biology Department, Woods Hole Oceanographic Institution, 266 Woods Hole Rd, Woods Hole, MA 02543, USA. ${ }^{2}$ Department of Biology, University of Southern Denmark, DK-5230 Odense M, Denmark. ${ }^{3}$ The University of Iceland's Research Center in Húsavík, 640 Húsavík, Iceland.

*Author for correspondence (amooney@whoi.edu)

T.A.M., 0000-0002-5098-3354
}

Received 15 August 2018; Accepted 3 January 2019
Slabbekoorn and Ripmeester, 2008), lower densities (Kuitunen et al., 1998), reduced breeding success (Kuitunen et al., 2003), altered age structures (Habib et al., 2007), reduced foraging effort (Quinn et al., 2006) and decreased foraging efficiency (Siemers and Schaub, 2011). Yet bird taxa are diverse, making it difficult to estimate noise impacts across species. A key but challenging step in understanding the impact of noise on any species is to first address what they are able to hear.

Much of what is known about hearing in birds comes from behavioral studies, often using time- and training-intensive operant conditioning methods on birds from laboratory colonies (Dooling, 1992; Okanoya and Dooling, 1987; Powell et al., 2018; Seki and Dooling, 2016). The auditory evoked potential (AEP) method has been used as an alternative and rapid physiological method to measure hearing (Brittan-Powell et al., 2002). It is used with many animal taxa, including humans and marine mammals, and involves measuring the neurological responses of the auditory system to controlled sounds (Burkhard et al., 2007; Mooney et al., 2012). The AEP procedures have been well established for multiple bird species for some time (Brittan-Powell et al., 2002). While the AEP method has been applied in field settings to odontocete species, methods differ and it has proved difficult to obtain audiograms in some other taxa (Houser et al., 2007).

To our knowledge, bird AEP studies have typically been limited to laboratory conditions, which facilitate acoustically quiet environments and easier control of neurophysiological measurements. Yet there would be substantial value in utilizing methods that allow assessments of hearing in wild birds in a minimally invasive manner. Such measurements would allow quantification of the sound sensitivity of a greater number of bird species and individuals, especially for those that are difficult to maintain in captivity, and thereby provide an avenue for investigating acoustic niche differences, population-level auditory variation, and the influences of both anthropogenic and natural noise on bird habitats and habitat use.

Seabirds are perhaps the most imperiled group of birds, with at least $25 \%$ of species listed as threatened and almost $50 \%$ of species in decline (Croxall et al., 2012; Lascelles et al., 2016). The status of many is listed as 'data deficient' (Lascelles et al., 2016). Seabirds readily transit between air and water and enact key behaviors in both habitats. With this amphibious lifestyle, they are likely faced with unique auditory constraints; unfortunately, like many other birds, anthropogenic noise seems to be a stressor. With humans increasingly utilizing many coastal areas, the soundscape of these areas is changing (Farina et al., 2014) and seabirds progressively face acoustic habitat degradation. Impacts include reduced colony and nest attendance associated with times of greater human visitor noise (Buxton et al., 2017) and a somewhat dose (sound level)-dependent influence of aircraft overflight noise, which induces various behaviors, including flying off at higher sound levels (Brown, 1990; Goudie and Jones, 2004). Recent laboratory efforts with the great cormorant (Phalacrocorax carbo) have demonstrated audiogram measurements using both psychophysical and neurophysiological auditory evoked 
potential methods (Hansen et al., 2017; Johansen et al., 2016; Maxwell et al., 2017). The laboratory-based auditory results suggest this species may have unique aquatically adapted hearing abilities.

Although the hearing studies noted above are pioneering, they utilized a coastal bird that closely associates with humans (Hansen et al., 2017; Johansen et al., 2016; Maxwell et al., 2017); similar laboratory studies may not be as successfully applied to other seabird species. Additional pelagic species may not be amenable to training or might not handle captive settings well. These studies were also limited in sample size as a result of the long process of psychophysical animal training and ethical constraints on the number of wild birds that can be brought into a laboratory setting. Additionally, in these and many other avian hearing studies, birds were typically not released back into the wild, and the experiments often utilized costly laboratory facilities. To generate larger data sets from wild birds, there is a need to develop efficient methods to measure hearing in the field.

The Auk family contains some species with highly derived and extreme secondary aquatic adaptations, including birds with impressive dive, physiological and behavioral capabilities (Barrett and Furness, 1990; Croll et al., 1992; Elliott et al., 2013; Enstipp et al., 2018). This taxon is particularly relevant to understanding the impact of underwater noise and acoustic health, given that two species of Auks are listed as endangered (the Guadalupe murrelet Synthliboramphus hypoleucus and the marbled murrelet Brachyramphus marmoratus) (BirdLife International, 2018a,c). Several other species, including the Atlantic puffin Fratercula arctica, are listed as vulnerable (BirdLife International, 2018b). Here, we describe an AEP method to estimate the audiograms of two wildcaught individuals of two respective seabird species from the family Alcidae in field-based conditions. Animals were caught, carefully anesthetized and placed in a field-derived semi-anechoic chamber where AEP measurements were performed. The animals were allowed to wake from sedation and were then successfully released at the capture site. The methods outlined are repeatable and likely applicable to other seabirds and avian species. To our knowledge, these are the first field-based hearing measurements of any bird species.

\section{MATERIALS AND METHODS}

\section{Animals and study sites}

We measured auditory evoked potentials from one Atlantic puffin [Fratercula arctica (Linnaeus 1758)] and one common murre [Uria aalge (Pontoppidan 1763)] on 2 and 3 June 2017, respectively. The puffin was caught using a $10 \times 1.5 \mathrm{~m}$ mesh net $(10$-cm-diameter eye size) strung across multiple burrows at a rookery on Tjörnes peninsula in northern Iceland. An animal exited the burrow for a foraging flight, became lightly caught in the net and was immediately $(<2 \mathrm{~min})$ and gently removed from the net by hand and placed in a soft black bird bag. It was transported directly to the hearing test site, a local farm shed, $\sim 1$ min drive away, which allowed us to conduct the tests away from wind and rain. The murre was obtained using a noose pole at a rookery on Langanes peninsula, northeastern Iceland. The bird was similarly placed in a black cloth bird bag and driven $\sim 1$ min down a dirt road to a hunter's cabin, which was used as a wind-break for the hearing tests.

The puffin and murre were immediately weighed (puffin: $365 \mathrm{~g}$; murre: $920 \mathrm{~g}$ ) and sedated with an intramuscular injection of a 2:1 ketamine hydrochloride:xylazine hydrochloride mixture at $20 \mathrm{mg} \mathrm{kg}^{-1}$. A supplementary dose was provided to each bird after $\sim 30 \mathrm{~min}$. The animals' heart rates were monitored with a stethoscope and body temperature was observed with a veterinary continuous digital anal monitor and probe (DataTherm II, model 501501); rates and temperatures were recorded every $5 \mathrm{~min}$. Body temperatures were ideally kept between 40.5 and $41.5^{\circ} \mathrm{C}$ while heart rates were $\sim 200$ beats $\mathrm{min}^{-1}$. To help maintain a calm bird, the bird bag was kept over the animals' heads during initial anesthesia and removed for the hearing tests. Animals were ready for the hearing tests $15-20$ min post-injection, as noted by a stable temperature, heart rate, respiration rate, minimal movement and closing of the eyes. Stable body temperatures were maintained by careful monitoring of the temperature probe and application of varied combinations of a heating blanket, a hot water bag (rarely used) and cool-water-soaked towels placed on the feet. Total holding time from capture to release for the puffin was $5 \mathrm{~h}, 1 \mathrm{~min}$; the murre was $5 \mathrm{~h} 40 \mathrm{~min}$. Data are available upon request. The permit for animal handling was provided by MAST (the Icelandic Food and Veterinary Authority). Work was conducted under a research permit from the Icelandic Environmental Agency permit and approved by the WHOI IACUC (\#BI21798.01).

\section{Acoustics and evoked potentials}

Hearing tests were conducted in a portable semi-anechoic chamber. This consisted of a large wire-frame dog kennel $(118 \times 84 \times 77 \mathrm{~cm})$ that was insulated on all inner sides with $4 \mathrm{~cm}$ of soft bedding foam, which served to insulate and reduce outside noise (Fig. 1A,B). We placed the self-contained, battery-powered speaker and amplifier (a Nagra DSM speaker, functional range: 60-15,000 Hz $\pm 4 \mathrm{~dB}$; Switzerland) used for the hearing tests at the far end of the kennel. During each examination, the animal was positioned on a bed liner near the kennel door with its head aligned toward the speaker. This allowed the researchers to easily monitor the animal's health status. The wire-frame door was removed and replaced with an insulated foam flap that flipped up and out of the way when needed, or closed during the hearing tests. Distance from the bird beak tip to the speaker was $68 \mathrm{~cm}$, allowing the animal to be out of the near field for all but the very lowest frequencies. The entire setup could be assembled in $\sim 10 \mathrm{~min}$ and easily broken down, placed in back of a vehicle and rebuilt in a new location.

Full calibrations, including background noise measurements and stimulus tones were made both at the puffin test area before and after the hearing tests, and stimuli and noise were monitored and recorded during each hearing test. The calibrations and sound level measurements were conducted by playing each hearing test stimulus at a constant attenuation level and recording the received sound pressure level using a precision sound level meter (type 2235, flat spectrum setting, Brüel \& Kjær, Nærum, Denmark) with its microphone (type 4176) placed near the bird's head. The received level of each stimulus was determined by the $\mathrm{dB}$ increase or decrease of the attenuator relative to this initial calibrated start value. The received tones were also measured during the hearing tests using a sound level meter and attenuations and received levels were as expected. To ensure proper spectral content of the stimuli, signals were digitally recorded using an M-Audio Microtrack II recorder (Irwindale, CA, USA) connected to the AC output of the sound level meter. Background noise measurements were similarly made using the sound meter microphone and saved on the Microtrack recorder. These data and the accuracy of the sound meter were assessed relative to a $94 \mathrm{~dB}$ calibration tone $(1 \mathrm{kHz}, 1 \mathrm{~Pa})$ from the calibrator of the sound level meter (type 4230, Brüel \& Kjær, Nærum, Denmark).

Hearing was tested using AEP methods similar to prior AEP studies in birds (Beatini et al., 2018; Brittan-Powell et al., 2002, 

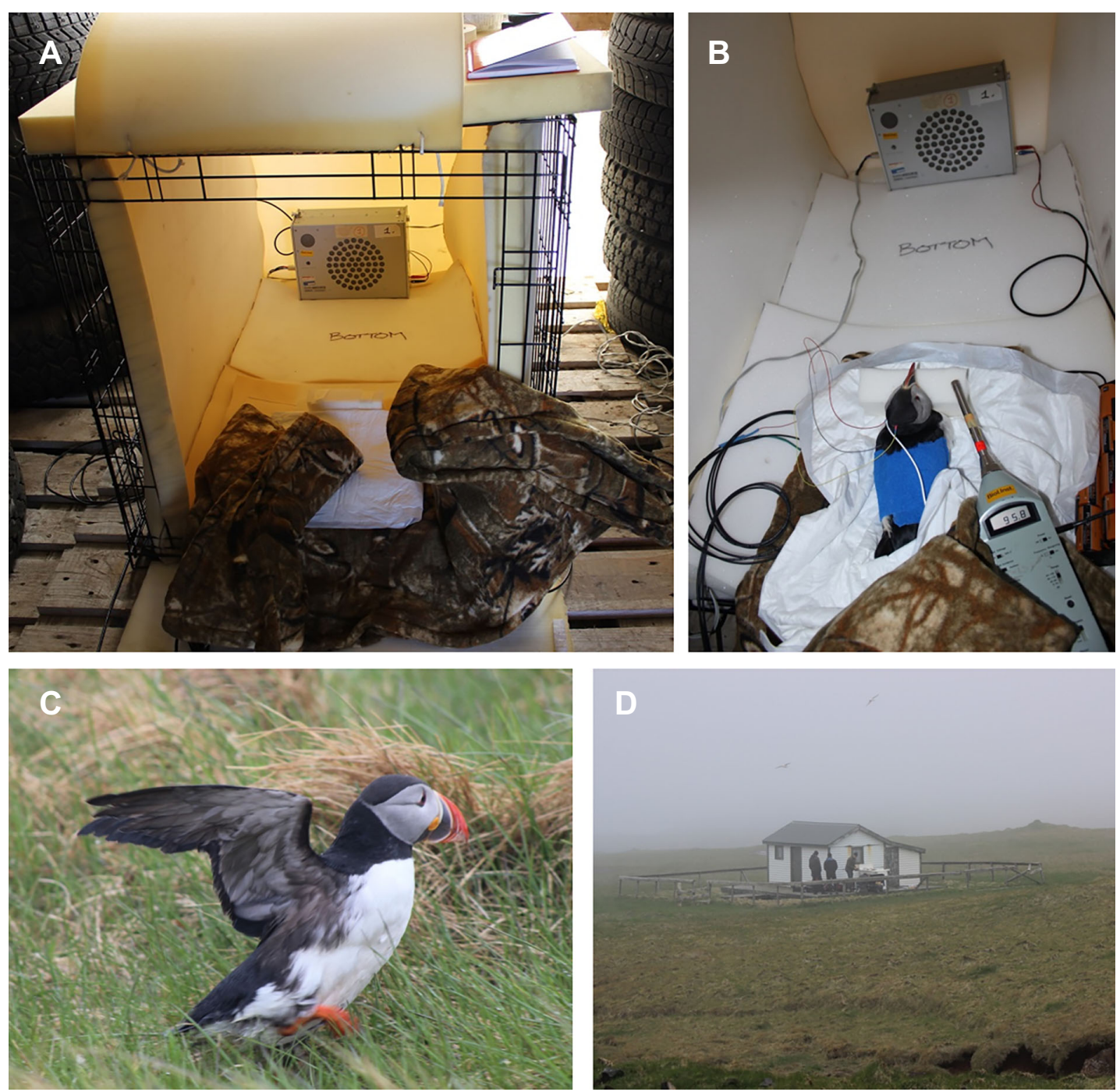

Fig. 1. Experimental setup and animal tested. (A) The semi-anechoic chamber lined with acoustically insulating foam. The speaker is at the far end, with heated blanket and bed-pad near the door. (B) The puffin during the AEP hearing test resting on a bed-pad and heated blanket. Electrodes are in place with the active electrode near the left ear. The sound level meter is to the right of the bird's head. (C) The puffin after release. (D) The location of the murre hearing test, Langanes peninsula, Iceland. The cabin offered a windbreak and is within $200 \mathrm{~m}$ of the rookery cliffs.

2005; Crowell et al., 2015; Henry and Lucas, 2010; Lohr et al., 2013; Maxwell et al., 2016). However, for the field study, the AEP equipment was outfitted in a rugged case. Examinations started with a broadband pulse consisting of two cycles of an $8 \mathrm{kHz}$ tone pip; the resulting signal was relatively broadband with $-10 \mathrm{~dB}$ energy from 4-12 kHz (see Fig. S1 for spectra) due to the short duration $(0.25 \mathrm{~ms})$ and rapid onset set of the signal. The auditory frequency range was then examined using tone pips of the following frequencies: $0.125,0.25,0.5,1,2,3,4$ and $6 \mathrm{kHz}$. The tones were $20 \mathrm{~ms}$ in duration except for the 0.25 and $0.5 \mathrm{kHz}$ tones, which were $40 \mathrm{~ms}$ in duration. All signals were digitally synthesized with a customized LabVIEW (National Instruments, Austin, TX, USA) data acquisition program and a National Instruments PCMCIA6062E data acquisition card implemented in a semi-ruggedized Panasonic Toughbook laptop computer. Each test signal was created using a $256 \mathrm{kHz}$ sample rate and presented at a rate of $10 \mathrm{~s}^{-1}$. Tone pips were ramped up to limit spectral spreading using a sine envelope, thus the maximum amplitude was found at the middle two waves, $\sim 10$ or $20 \mathrm{~ms}$, depending on the signal duration. Modulation of the brief tone created some minor sidebands (see Fig. S1), but these were $\sim 40 \mathrm{~dB}$ lower than the center frequency and minimal at low amplitudes (near thresholds), and were therefore not expected to impact hearing estimates (Supin and Popov, 2007).

Evoked potential recordings were made using three 30 gauge, uncoated, stainless steel needle electrodes inserted just under and parallel to the surface of the skin. The active electrode was placed just below the meatus of the anesthetized bird. The reference (inverting) electrode was attached at the vertex of the bird's head. A third ground electrode was inserted dorsally on the animals back. The AEP system was then grounded to the soil using a long copper wire attached to a $20 \mathrm{~cm}$ carbon-fiber rod inserted into the dirt.

The electrodes were connected to a biological amplifier (CP511, Grass Technologies, Warwick, RI, USA), which amplified all responses 5000-fold and bandpass filtered $(300-3000 \mathrm{~Hz})$ them. A second 8-pole Krohn-Hite DC-powered single channel filter (FMB300, Brockton, MA, USA) filter $(300-3000 \mathrm{~Hz})$ further conditioned the signals. The AEP data were finally recorded using the same DAQ card and custom laptop program. Responses were sampled at $16 \mathrm{kHz}$ with records beginning coincident with stimulus presentation. Stimuli were presented 750 times for each sound level 
and 750 corresponding AEP responses were averaged and stored for later data analyses. The summed average evoked response waveform was monitored at each sound level and stimuli were decreased in steps of 5-10 dB using an HP 350 D 5 W $600 \Omega$ DC attenuator until evoked responses were no longer visually detectable for two to three trials. If no response was notable or it was barely discernable relative to the background noise, sound levels were increased. Decibel step size was based on the amplitude of the signal and the animal's neurological response.

Audiogram thresholds were calculated offline. Records were initially viewed in the time domain (Fig. 2A-C). For a more confident extraction of the AEP waveform from the background noise, cross-correlation functions (CCFs) between the evaluated record and a standard AEP waveform were computed, using definite AEP to high-intensity stimuli as a standard. Fig. 2D exemplifies CCFs obtained for records presented in Fig. 2C. The CCFs had a positive peak at or near the zero lag. The CCF peak position was intensity dependent, with its delay lengthening and amplitude decreasing with each stimulus intensity decrease. To determine AEP hearing thresholds, the CCF peak magnitudes were plotted as a function of stimulus intensity expressed in $\mathrm{dB}$ (Fig. 2E). In a nearthreshold intensity range, these functions could be satisfactorily approximated by straight regression lines $\left(r^{2}=0.87\right.$ in Fig. 2). Intersection of the regression line with the zero-magnitude level was accepted as a threshold estimate. In the example presented in Fig. 2, this estimate was $50 \mathrm{~dB}$ re. $20 \mu \mathrm{Pa}$. Analyses were conducted using Excel (Microsoft) and MATLAB (MathWorks) software.

\section{RESULTS AND DISCUSSION}

Using the field-based methods described above, physiological AEP hearing measurements were made on two wild birds of two different auk species in field settings spatially close to their rookery and natural habitat. To our knowledge these are the first field-based hearing measurements of any bird species. Obtaining auditory data for seabirds is particularly valuable considering their conservation status, general population-level declines (Croxall et al., 2012; Lascelles et al., 2016) and the minimal understanding of how they may use or be influenced by their acoustic habitat. This includes the Atlantic puffin, which was only recently listed as vulnerable after rapid population declines in portions of its range (BirdLife International, 2018b). The method allows for the study of hearing in more species and greater numbers of individuals, thus supporting measurements of species and population-level variability. Consequently, we may be able to examine if a particular taxon has unique auditory adaptations or are more or less soundsensitive. Measuring hearing in wild animals also reduces the likelihood of examining only particular genetic lines with hearing limitations, as found in mice. Birds are adapted to hear in a noisy,
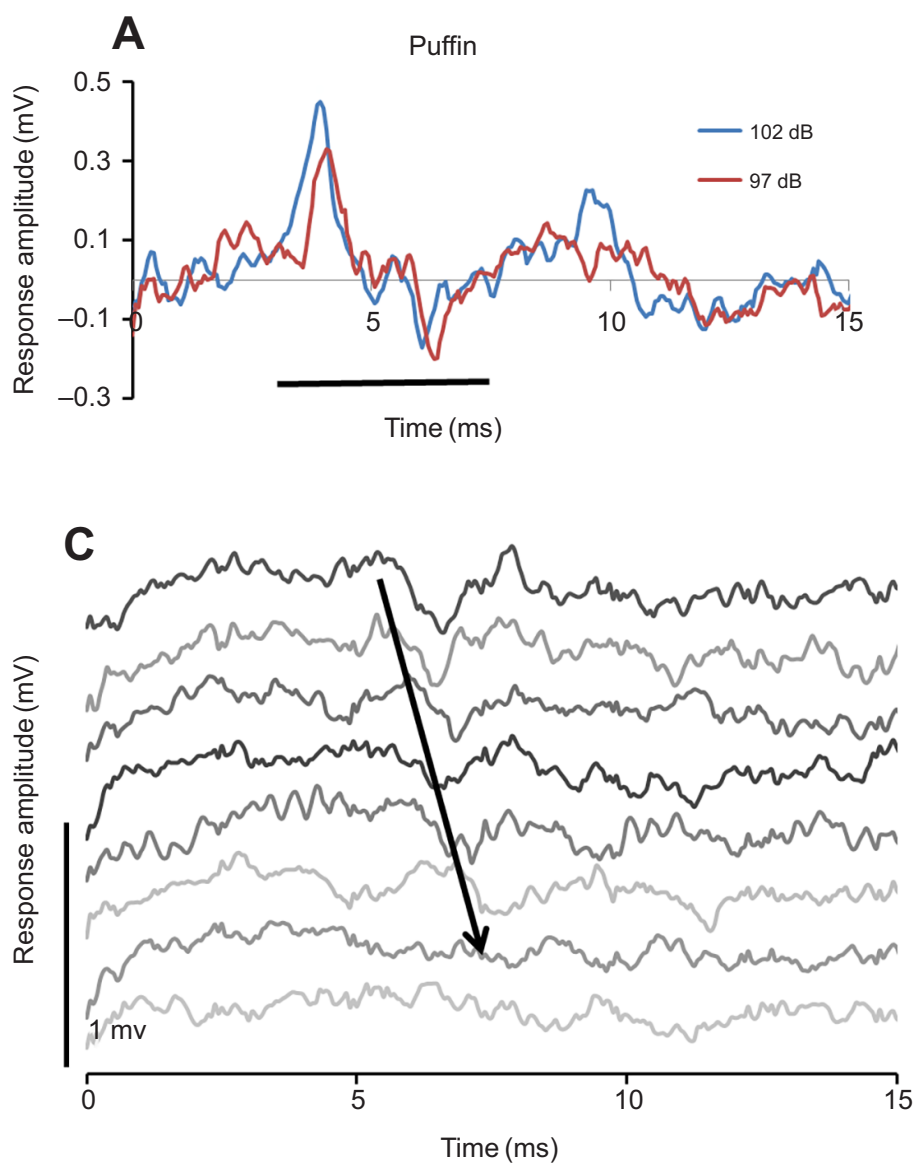
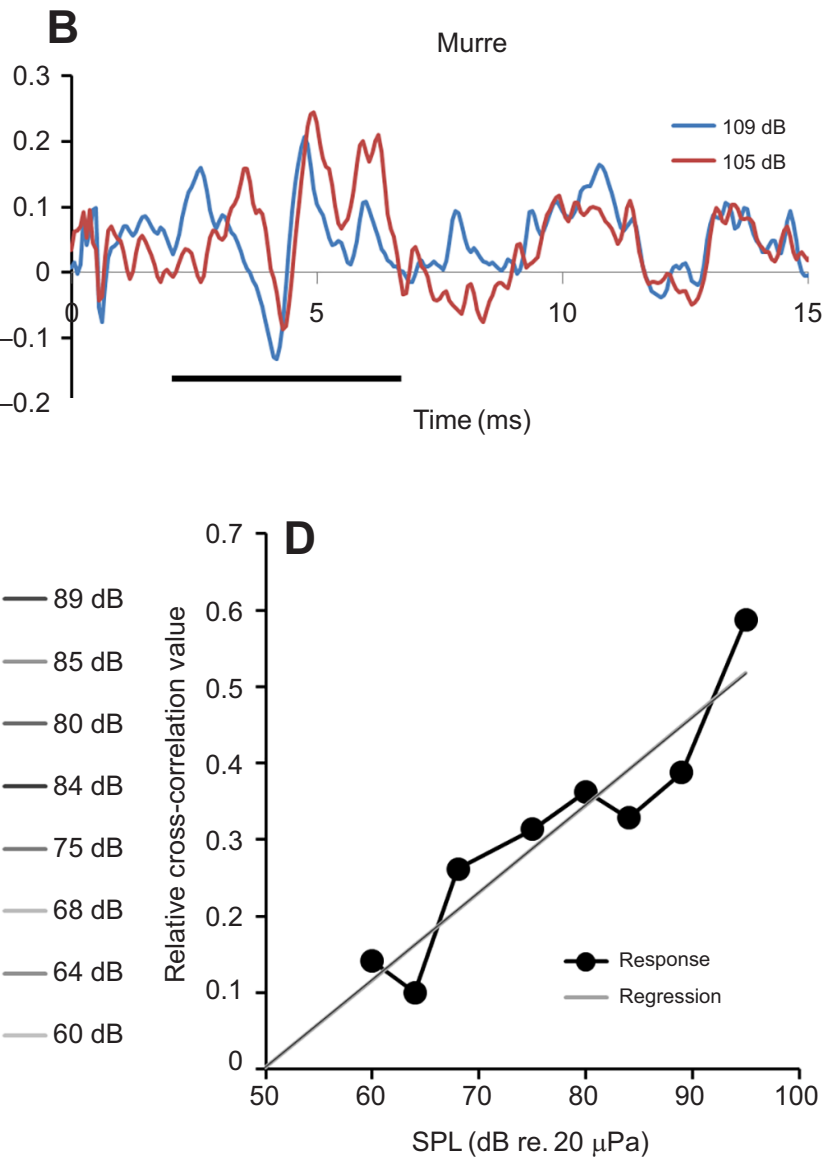

Fig. 2. AEP waveforms and threshold measurements. (A,B) Two waveform traces in response to different sound levels are shown for (A) the Atlantic puffin $F$. arctica and (B) common murre $U$. aalge. The responses are indicated with a black bar. Responses were relatively short latency (starting at $\sim 3-4$ ms). A slightly greater response delay is notable for the lower amplitude clicks. Beyond the initial peak AEPs there may be longer-delay, slower-wave responses. (C) Tone-generated AEP waveforms of the Atlantic puffin at eight different sound levels. Response indicated by the arrow. Again, a delay is notable as sound level decreases. The scale bar on the left is $1 \mu \mathrm{V}$. (D) Computing the threshold based on the CCF values for each frequency. The threshold for this $2 \mathrm{kHz}$ tone is $50 \mathrm{~dB}$. SPL, sound pressure level. 
reverberant world (Blumenrath and Dooling, 2010; Dooling and Blumenrath, 2016) and field studies allow us to compare hearing in the context of natural noise and the controlled, quiet methods used here.

Hearing data from the puffin were quite clear and provided an auditory curve that was not unlike AEP hearing thresholds in other birds, where the AEP thresholds generally are of the same shape but often 20-30 dB above hearing thresholds obtained by psychophysical methods (Beatini et al., 2018; Brittan-Powell et al., 2002, 2005; Crowell et al., 2015; Henry and Lucas, 2010; Lohr et al., 2013; Maxwell et al., 2016). Lowest measured thresholds were found at $1-2 \mathrm{kHz}$ with a gradual increase in AEP thresholds at lower frequencies and a steeper increase at higher frequencies (Fig. 3). Responses were measurable from 0.5 to $6 \mathrm{kHz}$. No discernable responses were noted at 0.125 and $0.25 \mathrm{kHz}$, which was likely a reflection of the limitation of tone-based AEP measurements at low frequencies rather than an impairment of the birds' hearing. The murre responses were substantially elevated compared with those in the puffin and the frequency range was narrower $(1-4 \mathrm{kHz}$ with no discernable responses at $3 \mathrm{kHz}$ ). Unfortunately, ambient noise measurements were not made at the murre testing site, but anecdotally, windier conditions likely caused higher acoustic noise levels.

An innate challenge of using AEP methods for birds is that this technique is not expected to provide absolute hearing thresholds; psychophysical audiograms tend to produce more-sensitive thresholds (Brittan-Powell et al., 2010). However, AEPs with good signal-to-noise ratios do provide a general range of hearing and can provide hearing threshold estimates. These test tones were brief by necessity of the method but durations were much shorter than the temporal integration time of some birds. In behavioral studies, similar duration tones would also result in thresholds elevated by $10-15 \mathrm{~dB}$ (Dooling and Searcy, 1985). In these measurements, the puffin responses were clear at higher sound levels, as expected, but responses from the murre often had higher noise levels. The average r.m.s. AEP response levels for the 5 blanks recorded was about twice as high for the murre $(0.0071 \pm 0.0098 \mu \mathrm{V}$; mean \pm s.d.) compared with the puffin $(0.0029 \pm 0.0040 \mu \mathrm{V})$. Consequently, lower amplitude responses in the murre seemed to be masked by neurophysiological noise. This noise (or the lower detectable responses) may have stemmed from multiple sources (location of electrodes, grounding, animal movement, muscular activity etc.) and time was limited, as was sample size (we were permitted to examine only one animal of each species), thus these factors were not methodically addressed. However, on average, body weight of the murre is approximately three times larger than that of the puffin. In other taxa, animal size and consequent distance of the recording electrode to the brainstem have been noted to reduce measured response amplitudes (Branstetter et al., 2017; Houser et al., 2007; Szymanski et al., 1999). If the murre's greater mass is taken as a proxy of its overall size, this size and increased distance from electrode to AEP generator may have affected our ability to measure its AEP responses. The murre was also vocalizing and moving slightly in its anesthesia-induced sleep about every minute, which raised neurological noise levels around each event. Presumably, with a larger sample size for murres, the degree of sedation and hence reduction of this noise could be addressed. The puffin audiogram was similar in threshold sound levels to the more sensitive thresholds measured by Crowell et al. (2015) for the ruddy duck, surf scoter and the black scoter. Also similar to here, AEPs were noisier and thresholds were higher for the northern gannet and the red-throated loon (Crowell et al., 2015), reflecting a consistency in need for reducing AEP noise levels, which supports the ability to measure lower, more-sensitive thresholds.

Eliminating background acoustic and physiological noise in the field, especially in a limited timeframe, is a challenging and important issue. The rookery was a relatively noisy place, with sounds from wind, waves, birdcalls and other sources (Fig. 3B). However, with the padding installed, our semi-anechoic crate offered a refuge from the ambient acoustic noise of exposed seabird colonies and the outdoors (Fig. 3B, gray line). The rookery sound levels recorded on the sound meter were $86-93 \mathrm{~dB}$ re. $20 \mu \mathrm{Pa}$ (linear scale), whereas inside the crate it was substantially lower at $63-66 \mathrm{~dB}$ re. $20 \mu \mathrm{Pa}$ (Fig. 3). With respect to physiological noise, one important step was being prepared for several grounding options. We tested several lengths of grounding wire as the terrain very near the puffin cabin was hard and mostly gravel, thus not an ideal location to bury grounding spikes. Longer wire allowed us the versatility to reach a suitable location (soil,

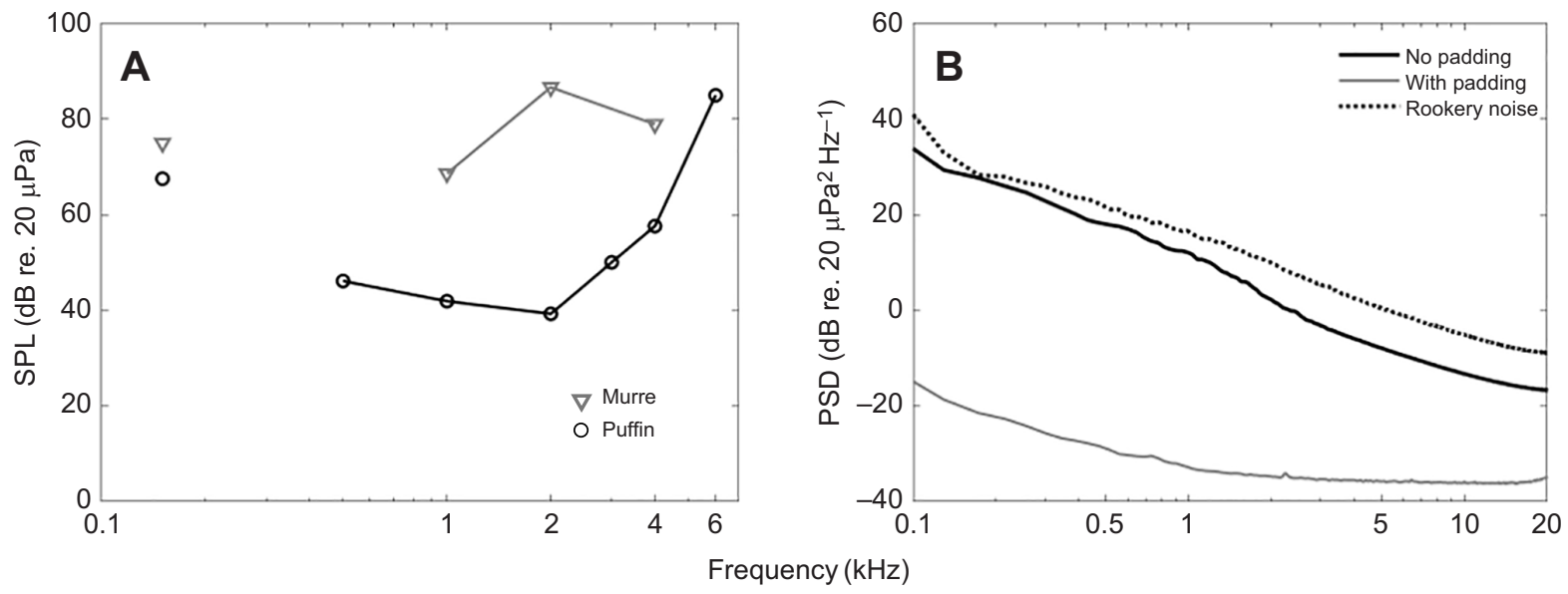

Fig. 3. AEP thresholds and background noise measurements. (A) AEP-calculated thresholds for the Atlantic puffin and common murre. The isolated points to the left are click-evoked response thresholds. SPL, sound pressure level in rms. (B) Relative ambient and background noise measurements in power

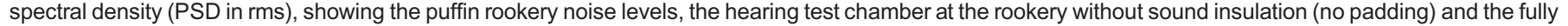
assembled hearing test chamber (shown in Fig. 1A,B) including sound-insulating foam padding. The crate measurements were made $~ 100 \mathrm{~m}$ from the cliff edge; a realistic distance for setting up a field station. 
rather than rock, $\sim 10 \mathrm{~m}$ from the hearing test area) to place the grounding spike.

Overall, this field-based audiometry represents a new step in bird acoustic ecology by enabling fast and flexible auditory measurements in more taxa and individuals of target species. Future studies could combine these hearing measurements with additional studies such as demography, genetics or health measurements (for hormones, parasites, contaminants etc.) (e.g. Mooney et al., 2018; Norman et al., 2012) to assess how hearing abilities may be associated with certain habitats, individual condition, relatedness and chronic stress. By combining hearing data with the acoustic environment around the birds and the frequency content and intensity of their communication sounds, we can address how changes in background noise levels may lead to masking and shorter communication ranges. With the new method to measure hearing in birds in the field, such studies can be made in a range of different sea birds and perhaps other avian taxa on a high number of individuals during a restricted field effort.

\section{Acknowledgements}

The authors thank Porkell Lindberg Pórarinsson of the Northeast Iceland Nature Research Centre for assistance locating bird colonies and catching birds.

\section{Competing interests}

The authors declare no competing or financial interests.

\section{Author contributions}

Conceptualization: T.A.M., M.W., M.H.R.; Methodology: T.A.M., A.S., O.N.L. K.A.H., M.W., M.H.R.; Software: T.A.M.; Validation: T.A.M., A.S., O.N.L.; Formal analysis: T.A.M., A.S., O.N.L.; Investigation: T.A.M., A.S., O.N.L., K.A.H., M.H.R.; Resources: T.A.M., M.H.R.; Data curation: T.A.M.; Writing - original draft: T.A.M.; Writing - review \& editing: T.A.M., A.S., O.N.L., K.A.H., M.W., M.H.R.; Visualization T.A.M., A.S.; Supervision: T.A.M., M.W., M.H.R.; Project administration: T.A.M., M.W., M.H.R.; Funding acquisition: T.A.M., M.W., M.H.R.

\section{Funding}

This work was supported by the U.S. Navy's Living Marine Resources Program and the Woods Hole Oceanographic Institution.

\section{Supplementary information}

Supplementary information available online at

http://jeb.biologists.org/lookup/doi/10.1242/jeb.190710.supplemental

\section{References}

Barrett, R. T. and Furness, R. W. (1990). The prey and diving depths of seabirds on Hornøy, North Norway after a decrease in the Barents Sea capelin stocks. Ornis Scandinavica 21, 179-186.

Beatini, J. R., Proudfoot, G. A. and Gall, M. D. (2018). Frequency sensitivity in Northern saw-whet owls (Aegolius acadicus). J. Comp. Physiol. A 204, 145-154.

BirdLife International (2018a). Species factsheet: Brachyramphus marmoratus. IUCN Red List for birds. Downloaded from http://www.birdlife.org on 11/07/2018. BirdLife International (2018b). Species factsheet: Fratercula arctica. IUCN Red List for birds. Downloaded from http://www.birdlife.org on 11/07/2018.

BirdLife International (2018c). Species factsheet: Synthliboramphus hypoleucus. IUCN Red List for birds. Downloaded from http://www.birdlife.org on 16/07/2018.

Blumenrath, S. H. and Dooling, R. J. (2010). Analyzing acoustic scenes in reverberant environments: a bird study. J. Acoust. Soc. Am. 127, 1895-1895.

Branstetter, B. K., St. Leger, J., Acton, D., Stewart, J., Houser, D., Finneran, J. J. and Jenkins, K. (2017). Killer whale (Orcinus orca) behavioral audiograms. J. Acoust. Soc. Am. 141, 2387-2398.

Brittan-Powell, E. F., Dooling, R. J. and Gleich, O. (2002). Auditory brainstem responses (ABR) in adult budgerigars (Melopsittacus undulatus). J. Acoust. Soc. Am. 112, 999-1008.

Brittan-Powell, E. F., Lohr, B., Hahn, D. C. and Dooling, R. J. (2005). Auditory brainstem responses in the eastern screech owl: an estimate of auditory thresholds. J. Acoust. Soc. Am. 118, 314-321

Brittan-Powell, E. F., Dooling, R. J., Ryals, B. and Gleich, O. (2010). Electrophysiological and morphological development of the inner ear in Belgian Waterslager canaries. Hear. Res. 269, 56-69.

Brown, A. L. (1990). Measuring the effect of aircraft noise on sea birds. Environ. Int. 16, 587-592.

Burger, J. and Gochfeld, M. (2004). Marine birds as sentinels of environmental pollution. EcoHealth 1, 263-274.
Burkhard, R. F., Eggermont, J. J. and Don, M. (2007). Auditory Evoked Potentials: Basic Principles and Clinical Applications. Philadelphia, PA: Lippincott, Williams and Wilkins.

Buxton, R. T., Galvan, R., McKenna, M. F., White, C. L. and Seher, V. (2017). Visitor noise at a nesting colony alters the behavior of a coastal seabird. Mar. Ecol. Prog. Ser. 570, 233-246.

Croll, D. A., Gaston, A. J., Burger, A. E. and Konnoff, D. (1992). Foraging behavior and physiological adaptation for diving in thick-billed murres. Ecology 73 , 344-356

Crowell, S. E., Wells-Berlin, A. M., Carr, C. E., Olsen, G. H., Therrien, R. E., Yannuzzi, S. E. and Ketten, D. R. (2015). A comparison of auditory brainstem responses across diving bird species. J. Comp. Physiol. A 201, 803-815.

Croxall, J. P., Butchart, S. H., Lascelles, B., Stattersfield, A. J., Sullivan, B., Symes, A. and Taylor, P. (2012). Seabird conservation status, threats and priority actions: a global assessment. Bird Conserv. Int. 22, 1-34.

Dooling, R. J. (1992). Hearing in birds. In The Evolutionary Biology of Hearing (ed. D. B. Webster, R. R. Fay and A. N. Popper), pp. 545-559. New York: Springer. Dooling, R. J. and Blumenrath, S. H. (2016). Masking experiments in humans and birds using anthropogenic noises. In The Effects of Noise on Aquatic Life II (ed. A. N. Popper and A. Hawkins), pp. 239-243. Springer.

Dooling, R. J. and Searcy, M. H. (1985). Temporal integration of acoustic signals by the budgerigar (M elopsittacusundulatus). J. Acoust. Soc. Am. 77, 1917-1920.

Dooling, R. J., Lohr, B. and Dent, M. L. (2000). Hearing in birds and reptiles. In Comparative hearing: Birds and reptiles (ed. R. J. Dooling, R. R. Fay and A. N. Popper), pp. 308-359: Springer

Elliott, K. H., Ricklefs, R. E., Gaston, A. J., Hatch, S. A., Speakman, J. R. and Davoren, G. K. (2013). High flight costs, but low dive costs, in auks support the biomechanical hypothesis for flightlessness in penguins. Proc. Natl Acad. Sci. USA 110, 9380-9384.

Enstipp, M. R., Descamps, S., Fort, J. and Grémillet, D. (2018). Almost like a whale-First evidence of suction feeding in a seabird. J. Exp. Biol. 221 jeb182170.

Farina, A., Buscaino, G., Ceraulo, M. and Pieretti, N. (2014). The soundscape approach for the assessment and conservation of Mediterranean landscapes: principles and case studies. J. Landscape Ecol. 7, 10-22.

Goudie, R. I. and Jones, I. L. (2004). Dose-response relationships of harlequin duck behaviour to noise from low-level military jet over-flights in central Labrador. Environ. Conserv. 31, 289-298.

Habib, L., Bayne, E. M. and Boutin, S. (2007). Chronic industrial noise affects pairing success and age structure of ovenbirds Seiurus aurocapilla. J. Appl. Ecol. 44, 176-184

Hansen, K. A., Maxwell, A., Siebert, U., Larsen, O. N. and Wahlberg, M. (2017) Great cormorants (Phalacrocorax carbo) can detect auditory cues while diving Sci. Nat. 104, 45.

Henry, K. S. and Lucas, J. R. (2010). Auditory sensitivity and the frequency selectivity of auditory filters in the Carolina chickadee, Poecile carolinensis. Anim. Behav. 80, 497-507.

Houser, D. S., Crocker, D. E., Reichmuth, C. J., Mulsow, J. and Finneran, J. J. (2007). Auditory evoked potentials in northern elephant seals (Mirounga angustirostris). Aquat. Mamm. 33, 110-121.

Johansen, S., Larsen, O. N., Christensen-Dalsgaard, J., Seidelin, L., Huulvej, T., Jensen, K., Lunneryd, S.-G., Boström, M. and Wahlberg, M. (2016). In-air and underwater hearing in the great cormorant (Phalacrocorax carbo sinensis). In The Effects of Noise on Aquatic Life II (ed. A. N. Popper and A. Hawkins) pp. 505-512. Springer.

Kettler, L., Christensen-Dalsgaard, J., Larsen, O. N. and Wagner, H. (2016). Low frequency eardrum directionality in the barn owl induced by sound transmission through the interaural canal. Biol. Cybern. 110, 333-343.

Kuitunen, M., Rossi, E. and Stenroos, A. (1998). Do highways influence density of land birds? Environ. Manag. 22, 297-302.

Lascelles, B., Rice, J., Sato, M., Tarzia, M. and Wanless, R. M. (2016). Seabirds United Nations Report. In First Global Marine Assessment. (ed. L. Inniss and A. Simcock), pp. 1-17. Division for Ocean Affairs and the Law of the Sea.

Lohr, B., Brittan-Powell, E. F. and Dooling, R. J. (2013). Auditory brainstem responses and auditory thresholds in woodpeckers. J. Acoust. Soc. Am. 133 337-342

Maxwell, A., Hansen, K. A., Larsen, O. N., Christensen-Dalsgaard, J., Wahlberg, M. and Siebert, U. (2016). Testing auditory sensitivity in the great cormorant (Phalacrocorax carbo sinensis): Psychophysics vs. Auditory brainstem response. In Proceedings of Meetings on Acoustics 4ENAL, Vol. 27, p. 050001 ASA.

Maxwell, A., Hansen, K. A., Ortiz, S. T., Larsen, O. N., Siebert, U. and Wahlberg, M. (2017). In-air hearing of the great cormorant (Phalacrocorax carbo). Biol. Open 6, 496-502.

Mooney, T. A., Yamato, M. and Branstetter, B. K. (2012). Hearing in cetaceans: from natural history to experimental biology. Adv. Mar. Biol. 63, 197-246.

Mooney, T. A., Castellote, M., Quakenbush, L., Hobbs, R., Gaglione, E. and Goertz, C. (2018). Variation in hearing within a wild population of beluga whales (Delphinapterus leucas). J. Exp. Biol. 221, jeb171959. 
Norman, S. A., Goertz, C. E. C., Burek, K. A., Quakenbush, L. T., Cornick, L. A., Romano, T. A., Spoon, T., Miller, W., Beckett, L. A. and Hobbs, R. C. (2012). Seasonal hematology and serum chemistry of wild beluga whales (Delphinapterus leucas) in Bristol Bay, Alaska, USA. J. Wildl. Dis. 48, 21-32.

Okanoya, K. and Dooling, R. J. (1987). Hearing in passerine and psittacine birds: a comparative study of absolute and masked auditory thresholds. J. Comp. Psychol. $101,7$.

Payne, R. S. (1971). Acoustic location of prey by barn owls (Tyto alba). J. Exp. Biol. 54, 535-573.

Powell, E. F., Manabe, K., Brown, S. D. and Dooling, R. J. (2018). The perceptual foundations of vocal learning in budgerigars. In Neuroethological Studies of Cognitive and Perceptual Processes (ed. C. F. Moss and S. J. Shettleworth), pp. 113-137. Routledge.

Proppe, D. S., Sturdy, C. B. and St Clair, C. C. (2013). Anthropogenic noise decreases urban songbird diversity and may contribute to homogenization. Glob. Change Biol. 19, 1075-1084.
Quinn, J. L., Whittingham, M., Butler, S. J. and Cresswell, W. (2006). Noise, predation risk compensation and vigilance in the chaffinch Fringilla coelebs. J. Avian Biol. 37, 601-608.

Seki, Y. and Dooling, R. J. (2016). Effect of auditory stimuli on conditioned vocal behavior of budgerigars. Behav. Process. 122, 87-89.

Siemers, B. M. and Schaub, A. (2011). Hunting at the highway: traffic noise reduces foraging efficiency in acoustic predators. Proc. R. Soc. B 278 1646-1652.

Slabbekoorn, H. and Ripmeester, E. A. (2008). Birdsong and anthropogenic noise: implications and applications for conservation. Mol. Ecol. 17, 72-83.

Supin, A. Y. and Popov, V. V. (2007). Improved techniques of evoked-potential audiometry in odontocetes. Aquat. Mamm. 33, 14-23.

Szymanski, M. D., Bain, D. E., Kiehl, K., Pennington, S., Wong, S. and Henry, K. R. (1999). Killer whale (Orcinus orca) hearing: auditory brainstem response and behavioral audiograms. J. Acoust. Soc. Am. 106, 1134-1141. 
Fig. S1. Recording of stimuli at the experimental site from the position of the bird. Spectra shown are (A) the broadband pulse and tones at 1, 2 and $4 \mathrm{kHz}(\mathrm{B}, \mathrm{C}$, and $\mathrm{D}$ respectively).
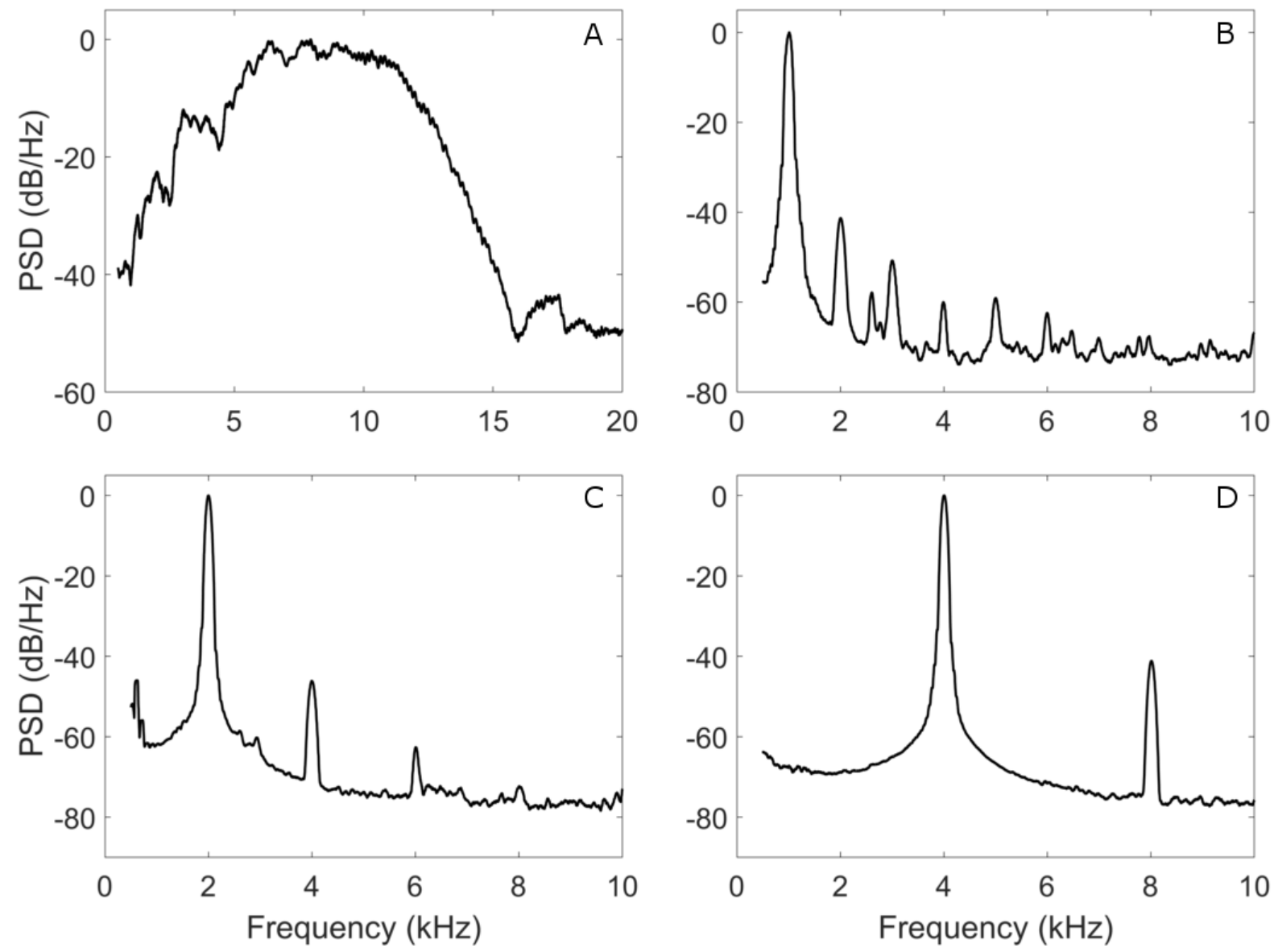